\title{
Analisis Faktor Perlindungan Matahari (FPM) dari Sediaan Tabir Surya secara Spektrofotometri dengan Metode Kuadrat Terkecil Sebagian Jack-Knife
}

\section{(Analysis of Sun Protection Factor (SPF) of Sunscreen Preparations by Spectrophotometry with Jack-Knife Partial Least Square)}

\author{
Dion Notario $^{1 *}$, Martanty Aditya ${ }^{2}$, Rollando $^{1}$, Kestrilia Rega Prilianti $^{2}$ \\ ${ }^{1}$ Program Studi Farmasi Universitas Ma Chung, Villa Puncak Tidar N-01, Malang \\ ${ }^{2}$ Program Studi Teknik Informatika Universitas Ma Chung, Villa Puncak Tidar N-01, Malang
}

\begin{abstract}
Determination in vitro of Sun Protection Factor (SPF) by using spectrophotometric method is needed to do initial screening of sunscreen active ingredients candidates. Nonetheless, relatively large errors were found when determination of SPF value of commercially available sunscreen preparation by spectrophotometric method was conducted. Therefore, in this research, SPF was analyzed spectrophotometrically at a wavelength of 290 - $320 \mathrm{~nm}$ continued by multivariate regression using jack-knife partial least squares in part to improve prediction accuracy of in vitro SPF. Furthermore, mathematical models were then used to screen sunscreen active ingredients of some botanical samples. The results showed that the resulting mathematical model has a value of prediction errors lower than the previous method (RMSECV $=3.15 ; \mathrm{r}=0.915$ ) and can be applied for screening sunscreen active ingredients candidates from plants.
\end{abstract}

Keywords: Sun Protection Factor, Spectrophotometry, Jack-Knife Partial Least Square

\section{ABSTRAK}

Penentuan nilai Faktor Perlindungan Matahari (FPM) dengan metode spektrofotometri sangat dibutuhkan untuk melakukan penapisan awal kandidat bahan aktif tabir surya. Meskipun demikian, ditemukan kesalahan yang relatif besar ketika dilakukan penentuan SPF secara spektrofotometrik terhadap beberapa sediaan tabir surya yang beredar secara komersial. Oleh karena itu, dalam penelitian ini dilakukan analisis FPM secara spektrofotometrik pada panjang gelombang 290 - $320 \mathrm{~nm}$ yang dilanjutkan dengan regresi multivariat yaitu kuadrat terkecil sebagian jack-knife untuk meningkatkan akurasi estimasi nilai prediksi FPM secara in vitro. Selanjutnya, model matematik yang diperoleh, digunakan untuk melakukan penapisan bahan aktif tabir surya dari beberapa sampel botani. Hasil penelitian menunjukkan bahwa model matematik yang dihasilkan mempunyai nilai kesalahan prediksi yang lebih rendah daripada metode sebelumnya $(\mathrm{RMSECV}=3,15 ; \mathrm{r}=0,915)$ dan dapat diaplikasikan untuk penapisan kandidat bahan aktif tabir surya dari tanaman.

Kata Kunci: Faktor Perlindungan Matahari, Spektrofotometri, Kuadrat Terkecil Sebagian Jack-Knife 


\section{LATAR BELAKANG}

Faktor perlindungan matahari (FPM) atau sun protection factor (SPF) merupakan salah satu parameter kuantitatif yang dijadikan sebagai tolak ukur kualitas sediaan tabir surya. Secara internasional, FPM dapat didefinisikan sebagai rasio antara dosis eritema minimal pada kulit manusia yang terlindungi oleh tabir surya $\left(\mathrm{DEM}_{\mathrm{p}}\right)$ dibandingkan dengan dengan dosis eritemal pada kulit manusia tanpa tabir surya $\left(D E M_{t}\right)$. Nilai $D_{E M}$ dan $D_{E M}$ dapat diukur dengan cara memberikan paparan sinar ultraviolet pada kulit manusia pada panjang gelombang $290-320 \mathrm{~nm}$ (UVB) sesuai dengan panduan ISO 24444 (ISO, 2010). Selanjutnya, nilai FPM dapat dikalkulasi dengan mensubstitusikan data $\mathrm{DEM}_{\mathrm{p}}$ dan $\mathrm{DEM}_{\mathrm{t}}$ pada persamaaan (1).

$$
\mathrm{FPM}=\frac{\mathrm{DEM}_{\mathrm{p}}}{\mathrm{DEM}_{\mathrm{t}}}
$$

Meskipun telah diakui sebagai metode standar, pengukuran nilai FPM secara in vivo memerlukan biaya besar dan waktu cukup panjang mengingat pengamatan eritema dilakukan terhadap subjek uji manusia selama $20 \pm 4$ jam setelah paparan. Oleh karena itu, sebelum dilakukan pengujian secara in vivo, perlu dilakukan penapisan bahan-bahan yang berpotensi sebagai bahan aktif tabir surya secara in vitro. Sampel uji yang telah terbukti memiliki nilai FPM yang cukup baik secara in vitro dapat diuji lebih lanjut dengan metode in vivo.

Beberapa metode pengukuran FPM secara in vitro yang dimanfaatkan sebagai metode penapisan kandidat bahan aktif tabir surya antara lain meliputi metode pegukuran FPM berdasarkan transmisi sinar ultraviolet melewati suatu membran/plat dan metode Mansur. Pengukuran nilai FPM dengan transmisi sinar ultraviolet dilakukan dengan cara mengoleskan $30 \mathrm{mg}$ tabir surya yang diuji ke permukaan plat misalnya PMMA (polimetilmetakrilat) seluas $25 \mathrm{~cm}^{2}$ kemudian dilakukan pengukuran transmitan pada panjang gelombang tertentu, yang disimbolkan dengan $\mathrm{T}(\lambda)$, menggunakan UV Transmittance Analyzer (Chauvet et al., 2012). Nilai FPM dengan metode ini dikalkulasi sesuai dengan persamaan (2) di mana $S(\lambda)$ adalah radiasi spektral sinar matahari pada kondisi tertentu, sedangkan $\operatorname{EA}(\lambda)$ adalah efektivitas relatif radiasi ultraviolet pada panjang gelombang $\lambda$ untuk pembentukan eritema pada kulit manusia. Baik nilai $S(\lambda)$ maupun $\operatorname{EA}(\lambda)$ merupakan nilai tetap yang dapat ditemukan dalam literatur (Diffey \& Robson, 1989; Herzog, 2002; Sayre et al., 1979).

$$
\mathrm{FPM}=\frac{\sum_{290}^{320} \mathrm{~S}(\lambda) \cdot \mathrm{EA}(\lambda)}{\sum_{290}^{320} \mathrm{~S}(\lambda) \cdot \mathrm{EA}(\lambda) \cdot \mathrm{T}(\lambda)}
$$


Metode pengukuran FPM selanjutnya adalah metode Mansur. Sampel yang diuji dengan metode Mansur mula-mula dilarutkan dengan etanol hingga konsentrasi $2 \mathrm{mg} / \mathrm{mL}$ atau $2 \mu \mathrm{L} / \mathrm{mL}$ untuk sampel padat/semipadat atau cair, kemudian dilakukan pengukuran absorbansi pada panjang gelombang 290 $320 \mathrm{~nm}$ dengan interval $5 \mathrm{~nm}$. Nilai FPM dikalkulasi menggunakan persamaan (3), dikenal dengan persamaan Mansur, dengan mensubstitusikan nilai FK = faktor koreksi (10); $\operatorname{EE}(\lambda)$; I $(\lambda)$; dan $\operatorname{Abs}(\lambda)$ yang secara berurutan merupakan efek eritemal; intensitas sinar; dan absorbansi pada panjang gelombang $290-320 \mathrm{~nm}$ dengan interval $5 \mathrm{~nm}$ (Mansur et al., 2016; Mishra et al., 2012).

$$
\mathrm{FPM}=\mathrm{FK} \times \sum_{290}^{320} \mathrm{EE}(\lambda) \times \mathrm{I}(\lambda) \times \operatorname{Abs}(\lambda)
$$

Metode Mansur merupakan metode yang paling sederhana sehingga banyak digunakan sebagai metode penapisan awal bahan aktif tabir surya. Dalam proses kalkulasi nilai FPM, diketahui bahwa hasil kali $\operatorname{EE}(\lambda)$ dan $\mathrm{I}(\lambda)$ merupakan suatu tetapan yang diperoleh dari literatur (Sayre et al., 1979), sedangkan $\mathrm{A}(\lambda)$ diperoleh dari percobaan. Berdasarkan persamaan Mansur, nilai FPM dapat dinyatakan sebagai fungsi dari absorbansi larutan sampel pada panjang gelombang $290-320$ $\mathrm{nm}$ dengan interval $5 \mathrm{~nm}$ yang secara matematis dapat dituliskan dalam persamaan (4) yang merupakan persamaan regresi linear multivariat di mana $\beta$ adalah suatu tetapan sedangkan A adalah absorbansi larutan pada panjang gelombang tertentu $(290-320 \mathrm{~nm})$.

$$
\begin{aligned}
\mathrm{FPM}= & \beta_{1} \mathrm{~A}_{290}+\beta_{2} \mathrm{~A}_{295}+\beta_{3} \mathrm{~A}_{300}+\beta_{4} \mathrm{~A}_{305}+ \\
& \beta_{5} \mathrm{~A}_{310}+\beta_{6} \mathrm{~A}_{315}+\beta_{7} \mathrm{~A}_{320}
\end{aligned}
$$

Oleh karena nilai FPM merupakan fungsi linear dari absorbansi larutan sampel pada panjang gelombang $290-320 \mathrm{~nm}$, maka dapat dilakukan analisis regresi linear multivariat untuk mengkaji hubungan antara FPM dengan absorbansi larutan pada konsentrasi tertentu. Analisis regresi linear multivariat dapat dilakukan dengan beberapa metode antara lain dengan regresi linear berganda (RLB), regresi komponen utama (RKU), dan kuadrat terkecil sebagian (KTS).

Dalam regresi linear berganda salah satu permasalahan yang umum ditemui adalah multikolinearitas yang menyebabkan estimasi nilai $\beta$ tidak stabil. Oleh karena itu, diperlukan metode regresi linear multivariat yang mampu mengatasi masalah multikolinearitas salah satunya adalah KTS jack-knife. Selain mengatasi multikolinearitas dalam regresi multivariat, penggunaan KTS jack-knife dapat mengestimasi nilai-nilai sekaligus standar error dan signifikansi koefisien-koefisien regresi (Ismartini and Sunaryo, 2010; Wold et al., 1984). Dengan demikian, metode 
KTS jack-knife dapat digunakan untuk memprediksi nilai FPM secara spektrofotometri.

Penelitian ini dilakukan untuk mengkaji hasil prediksi nilai FPM secara spektrofotometri dengan metode Mansur dibandingkan metode KTS jack-knife. Model matematik yang diperoleh dari KTS selanjutnya digunakan untuk melakukan penapisan bahan alam sebagai kandidat bahan aktif tabir surya. Dengan demikian, dapat diperoleh metode penapisan FPM secara statistik yang lebih jauh dapat menambah khazanah ilmu pengetahuan di bidang kosmetologi.

\section{BAHAN DAN METODE}

Alat

Seperangkat alat spektrofotometer BlueStar series (LabTech), kuvet kuarsa, rotary evaporator, penangas air, sonikator, dan alat-alat gelas.

\section{Bahan}

Etanol 96\%, akuades, etil asetat, simplisia kulit batang faloak, daun andong merah, dan daun kangkung.

\section{Penentuan Nilai FPM Sediaan Tabir Surya Komersial}

Sebanyak $100 \mathrm{mg}$ sediaan tabir surya ditimbang dengan seksama kemudian dilarutkan dalam sebagian etanol dengan bantuan gelombang ultrasonik. Larutan ini dipindahkan secara kuantitatif ke dalam labu ukur $50 \mathrm{~mL}$ kemudian ditambahkan etanol sampai tanda kalibrasi. Larutan ini selanjutnya disebut dengan larutan A (2 $\mathrm{mg} / \mathrm{mL}$ ). Selanjutnya, sebanyak 4,0; 2,0; dan 1,0 $\mathrm{mL}$ larutan A dipindahkan ke dalam tiga labu ukur $10 \mathrm{~mL}$ yang berbeda kemudian ditambahkan etanol 96\% sampai tanda kalibrasi sehingga dihasilkan larutan B, C, dan D dengan konsentrasi sebesar 0,$8 ; 0,4$; dan $0,2 \mathrm{mg} / \mathrm{mL}$ secara berurutan. Masing-masing larutan A, B, C, dan D diukur serapannya pada panjang gelombang $290-320 \mathrm{~nm}$ dengan interval $5 \mathrm{~nm}$ dan dihitung nilai FPM menggunakan persamaan (3).

\section{Penyiapan Serbuk Sampel}

Sampel tanaman yang telah dipanen dipotong kecil-kecil kemudian dikeringkan di bawah sinar matahari. Selanjutnya, simplisia yang telah kering diserbuk menggunakan grinder kemudian disimpan sampai tahap selanjutnya.

\section{Ekstraksi \\ Prosedur A}

Serbuk sampel direndam dalam etanol $96 \%$ dengan perbandingan $1: 6 \mathrm{w} / \mathrm{v}$ selama 48 jam dengan pengadukan sesering mungkin kemudian disaring. Filtrat ditampung dalam wadah yang sesuai sedangkan ampas dicuci menggunakan etanol $96 \%$ dengan perbandingan 1:1 sambil diaduk sesering mungkin kemudian disaring. Langkah ini 
dilakukan secara berulang kali hingga diperoleh filtrat yang tidak berwarna. Filtrat diuapkan dengan rotary evaporator pada suhu $80 \pm 2{ }^{\circ} \mathrm{C}$ sehingga diperoleh ekstrak kental. Ekstrak kental ini dipindahkan ke dalam cawan porselen lalu diuapkan lebih lanjut di atas penangas air. Selanjutnya, ekstrak dikeringkan dalam oven pada suhu $50 \pm 2^{\circ} \mathrm{C}$ selama 24 jam, kemudian dipindahkan ke dalam desikator. Ekstrak kering dilarutkan dalam akuades dan dilakukan proses ekstraksi cair-cair menggunakan pelarut etil asetat dengan perbandingan fase air dan etil asetat 1:1. Prosedur ekstraksi cair-cair ini dilakukan sampai didapati fraksi etil asetat yang tidak berwarna. Fase etil asetat diuapkan diatas penangas air kemudian dikeringkan dalam desikator.

\section{Prosedur B}

Serbuk sampel direndam dalam etil asetat dengan perbandingan 1:6 kemudian diekstraksi dengan bantuan gelombang ultrasonik selama 45 menit pada suhu $75^{\circ} \mathrm{C}$ $\pm 2^{\circ} \mathrm{C}$ dan daya $90 \%$ dari kekuatan maksimal. Selanjutnya, dilakukan penyaringan kemudian filtrat dikumpulkan, diuapkan, dan dikeringkan sama seperti pada prosedur A sedangkan ampas diekstraksi kembali dengan etil asetat dingin beberapa kali sampai diperoleh filtrat yang tidak berwarna. Ampas dikeringkan dan diekstraksi dengan pelarut etanol 96\% menggunakan gelombang ultrasonik selama 30 menit pada suhu $75^{\circ} \mathrm{C}$ $\pm 2^{\circ} \mathrm{C}$ dan daya $90 \%$ dari kekuatan maksimal. Sampel disaring kemudian ampas dicuci dengan etanol dingin beberapa kali sampai diperoleh filtrat yang tidak berwarna. Selanjutnya filtrat dikumpulkan, diuapkan, dan dikeringkan sama seperti prosedur A.

\section{Pembuatan Sampel Tabir Surya Simulasi}

Sampel krim simulasi dibuat dengan cara sebagai berikut: mula-mula ditimbang bahan-bahan seperti pada Tabel 1 kemudian dikelompokkan menjadi menjadi dua yaitu campuran A dan campuran B. Campuran A terdiri dari ekstrak, tween 80, minyak zaitun, dan spermaseti (beaker glass I) sedangkan campuran B terdiri dari gliserin dan metil paraben (beaker glass II). Bahan-bahan pada campuran A dan campuran B dipanaskan masing-masing hingga mencapai suhu $70^{\circ} \mathrm{C}$ yang disertai dengan pengadukan. Selanjutnya, campuran B dimasukkan ke dalam campuran A pelan-pelan pada suhu suhu $70^{\circ} \mathrm{C}$ sambil diaduk. Setelah homogen, campuran dibiarkan mencapai suhu kamar sambil terus diaduk. 
Tabel 1. Formula Sampel Tabir Surya Simulasi

\begin{tabular}{|l|r|}
\hline Bahan & Jumlah $(\mathbf{\%} \mathbf{b} / \mathbf{b})$ \\
\hline Ekstrak & 10 \\
\hline Akuades & 70,5 \\
\hline Metil paraben & 0,025 \\
\hline Tween 80 & 7,5 \\
\hline Minyak zaitun & 2 \\
\hline Spermaseti & 5 \\
\hline Gliserin & 5 \\
\hline
\end{tabular}

\section{Penentuan Nilai FPM Sampel Uji}

Sebanyak 100 mg sampel dilarutkan dalam $25 \mathrm{~mL}$ etanol $96 \%$ dengan bantuan gelombang ultrasonik selama 5 menit pada suhu kamar. Larutan dipindahkan secara kuantitatif ke dalam labu takar $50 \mathrm{~mL}$ kemudian ditambahkan etanol $96 \%$ sampai tanda kalibrasi. Satu mL larutan dipindahkan dengan seksama ke dalam labu takar $10 \mathrm{~mL}$ kemudian diencerkan dengan etanol 96\% sampai tanda kalibrasi. Larutan ini disaring dan diukur absorbansinya pada panjang gelombang $290-320 \mathrm{~nm}$ dengan interval $5 \mathrm{~nm}$.

\section{Analisis Statistik}

Nilai FPM dengan metode Mansur dihitung dengan mengaplikasikan persamaan Mansur pada MS Excel 2016, plot FPM label dan hasil prediksi dibuat dengan perangkat lunak R, kalkulasi KTS jackknife dikalkulasi menggunakan perangkat lunak $\mathrm{R}$ dengan paket pls (Bjørn-Helge Mevik, 2015).

\section{HASIL DAN PEMBAHASAN}

Pengukuran nilai FPM dengan metode Mansur perlu diverifikasi untuk mengetahui seberapa dekat nilai-nilai FPM hasil prediksi dengan nilai-nilai yang tertera pada label. Oleh karena itu, dilakukan beberapa seri percobaan untuk penentuan FPM dengan metode Mansur. Dalam penelitian ini, dilakukan empat seri percobaan penentuan FPM dengan beberapa konsentrasi yaitu $2 ; 0,8 ; 0,4$; dan $0,2 \mathrm{mg} / \mathrm{mL}$.

Berdasarkan hasil pengukuran nilai FPM yang dilakukan terhadap beberapa sediaan tabir surya komersial, dapat diketahui bahwa pada konsentrasi larutan sampel sebesar $2 \mathrm{mg} / \mathrm{mL}$, hasil prediksi FPM sangat berbeda jauh dengan nilai FPM pada label, bahkan cenderung sama (Gambar 1 A). Pada konsentrasi 0,8 mg/mL ada tiga hasil prediksi FPM pada sediaan tabir surya komersial yang mendekati nilai yang tertera pada label yaitu sediaan dengan FPM 15, 21, dan 24 (Gambar 1 B). Pada konsentrasi $0,4 \mathrm{mg} / \mathrm{mL}$ hanya ada satu hasil prediksi FPM yang mendekati nilai yang tertera pada label yaitu sediaan dengan FPM 35 (Gambar 1 C) sedangkan pada konsentrasi $0,2 \mathrm{mg} / \mathrm{mL}$ nilai FPM hasil prediksi sangat jauh dari nilai yang tertera pada label (Gambar 1 D). 

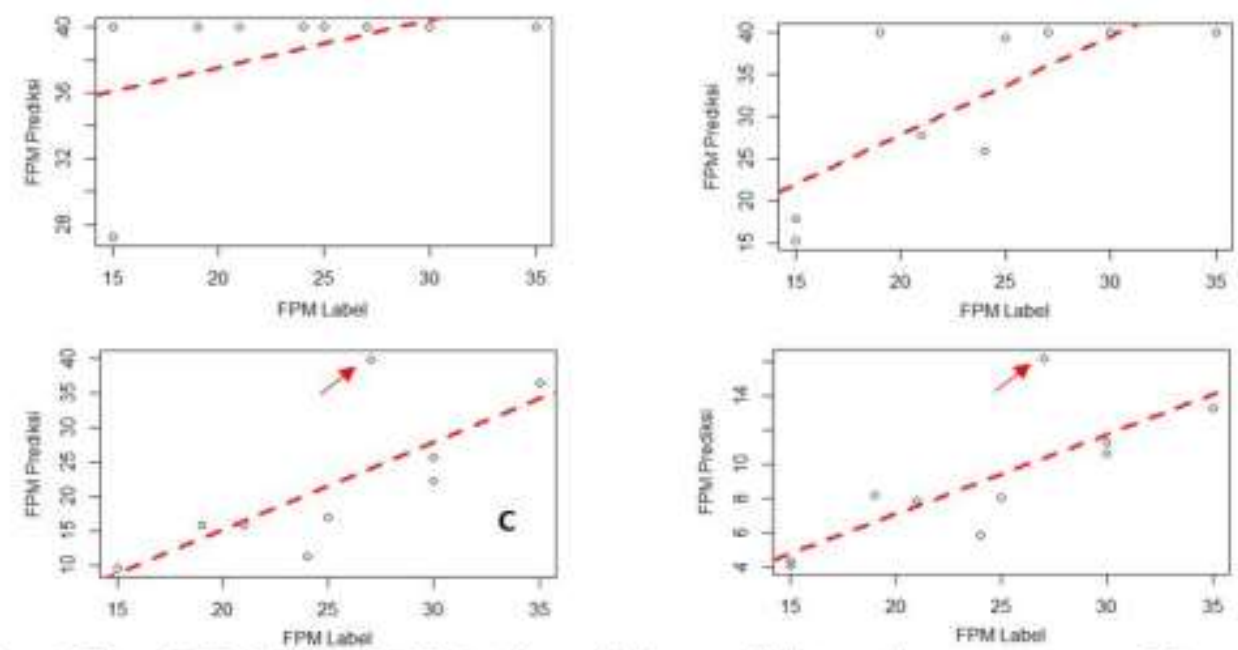

Gambar 1. Plot FPM Label vs FPM hasil prediksi yang dihitung dengan persamaan Mansur pada beberapa sediaan tabir surya yang tersedia secara komersial. A $=2 \mathrm{mg} / \mathrm{mL}, \mathrm{B}=0,8 \mathrm{mg} / \mathrm{mL}$, $\mathrm{C}=0,4 \mathrm{mg} / \mathrm{mL}, \mathrm{D}=0,2 \mathrm{mg} / \mathrm{mL}$. Tanda panah warna merah menunjukkan adanya pencilan (outlier)

Pola sebaran data pada Gambar 1 A menunjukkan bahwa metode Mansur memiliki kesalahan yang cukup besar dalam memprediksi nilai FPM pada sediaan tabir surya pada rentang 15 - 35. Pada saat konsentrasi sampel dibuat lebih encer yaitu 0,8 mg/mL (Gambar 1 B), metode Mansur mampu memprediksi sediaan tabir surya dengan baik pada sediaan dengan nilai FPM sekitar 15 dan 25. Di lain pihak, pada konsentrasi kecil yaitu pada 0,4 dan 0,2 $\mathrm{mg} / \mathrm{mL}$ nilai FPM hasil prediksi jauh berbeda dengan nilai yang tertera pada label, tetapi menunjukkan hubungan yang linear meskipun didapati satu pencilan pada kelompok data hasil eksperimen (Gambar 1 C dan D). Oleh karena itu, dengan menggunakan data-data larutan D, dikembangkan suatu model prediksi yang baru dengan memanfaatkan regresi multivariat yaitu KTS jack-knife.
Pemodelan persamaan regresi dengan kuadrat terkecil sebagian menghasilkan nilai-nilai prediksi yang jauh lebih baik dibandingkan dengan persamaan Mansur. Kedekatan antara FPM hasil prediksi dengan nilai yang tertera pada label dapat dilihat pada Gambar 2 yang merupakan model terbaik dari seri percobaan yang dilakukan di mana semua variabel independen $\left(x_{1}-x_{7}\right)$ memiliki nilai signifikansi yang tinggi $(\mathrm{p}<0,05)$.

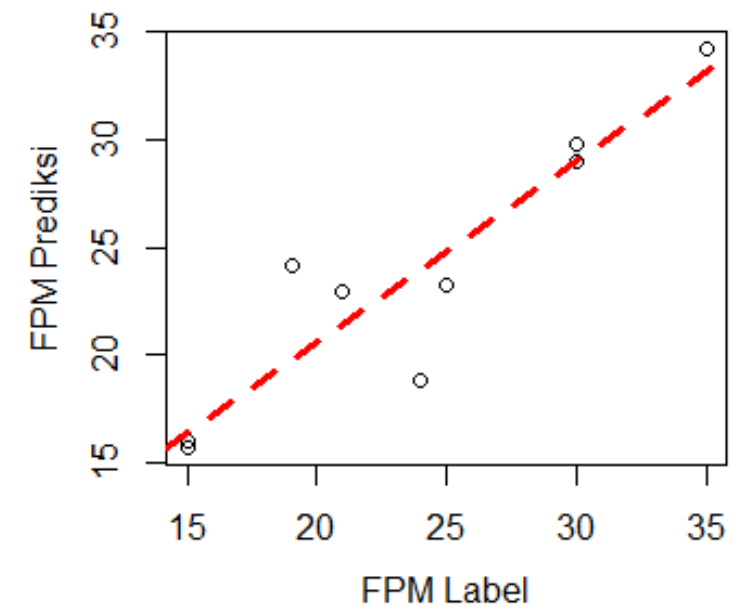

Gambar 2. Plot FPM Label vs Hasil Prediksi pada Sediaan Tabir Surya Komersial yang Dikalkulasi dengan Kuadrat Terkecil Sebagian 
dengan jumlah komponen sebesar satu. Konsentrasi larutan sampel sebesar $0,2 \mathrm{mg} / \mathrm{mL}$

Dalam model ini, dipilih jumlah komponen yang menghasilkan nilai RMSECV (root mean square error of cross validation) paling kecil yaitu satu sehingga kesalahan prediksi menjadi minimal. Model persamaan yang dihasilkan memiliki koefisien korelasi yang cukup tinggi sebesar 0,916 dengan akar kuadrat rata-rata kesalahan prediksi sebesar 3,15 (Tabel 2). Nilai kesalahan prediksi relatif cukup besar apabila dibandingkan dengan kesalahan acak (replikasi) sehingga dalam penentuan nilai FPM, nilai kesalahan prediksi selalu diikutsertakan dalam perhitungan dan dituliskan dalam hasil akhir (Tabel 3). Model persamaan yang diperoleh dengan metode KTS jack-knife digunakan untuk mengesimasi nilai FPM dari beberapa sampel botani antara lain kulit batang faloak, kangkung, dan andong merah. Berdasarkan hasil pengukuran nilai FPM masing-masing sampel dapat disimpulkan bahwa ekstrak etanolik daun andong merah mempunyai potensi yang paling besar sebagai bahan aktif tabir surya (Tabel 3) sehingga ekstrak andong merah memiliki potensi untuk diproses lebih lanjut menjadi sediaan tabir surya. Ekstrak tanaman yang lain memiliki nilai FPM yang relatif kecil sehingga tidak diproses lebih lanjut. Setelah diformulasikan dalam bentuk krim, diperoleh nilai FPM ekstrak andong merah adalah sebesar $6,71 \pm 3,15$.

Berdasarkan penelitian ini, dapat diketahui bahwa teknik KTS jack-knife dapat digunakan sebagai alternatif dalam memodelkan hubungan antara nilai FPM dengan absorbansi larutan sampel yang diukur secara spektrofotometri. Model persamaan matematik yang digunakan terbukti mampu menghasilkan nilai-nilai prediksi dengan kesalahan yang lebih kecil dibandingkan dengan metode Mansur. Lebih jauh lagi, model matematik yang diperoleh dapat dimanfaatkan untuk melakukan penapisan kandidat bahan aktif tabir surya. Dengan demikian dapat disimpulkan bahwa analisis nilai FPM yang dilakukan dengan metode spektrofotometri dan KTS jack-knife memiliki akurasi nilai prediksi yang lebih tinggi daripada metode Mansur dan dapat diaplikasikan dalam penapisan bahan aktif alami tabir surya.

\section{UCAPAN TERIMAKASIH}

Penulis menghaturkan banyak terimakasih kepada Lembaga Penelitian dan Pengabdian Masyarakat Universitas Ma Chung atas bantuan dana penelitian serta kepada Program Studi Farmasi Universitas Ma Chung atas penyediaan fasilitas laboratorium selama penelitian berlangsung. 
Tabel 2. Perhitungan koefisien masing-masing variabel independen

\begin{tabular}{|c|r|c|r|r|c|c|}
\hline Variabel & Estimasi & SE & df & t-hitung & P & Kode Signifikansi \\
\hline$x_{1}$ & 2,84044 & 0,31859 & 8 & 8,9156 & $1,99 \times 10^{-5}$ & $* * *$ \\
\hline$x_{2}$ & 3,00376 & 0,32847 & 8 & 9,1446 & $1,65 \times 10^{-5}$ & $* * *$ \\
\hline$x_{3}$ & 3,08288 & 0,34211 & 8 & 9,0113 & $1,84 \times 10^{-5}$ & $* * *$ \\
\hline$x_{4}$ & 3,20945 & 0,33606 & 8 & 9,5503 & $1,20 \times 10^{-5}$ & $* * *$ \\
\hline$x_{5}$ & 3,28754 & 0,36146 & 8 & 9,0952 & $1,72 \times 10^{-5}$ & $* * *$ \\
\hline$x_{6}$ & 3,07403 & 0,37047 & 8 & 8,2978 & $3,35 \times 10^{-5}$ & $* * *$ \\
\hline$x_{7}$ & 2,39424 & 0,38205 & 8 & 6,2669 & $2,41 \times 10^{-4}$ & $* * *$ \\
\hline
\end{tabular}

Kode Signifikansi: 0 '***'; 0,001 '**'; 0,01 '*'; 0,05 '.' ;0,1 ' ' 1; nilai $r=0,916$; RMSECV $($ root mean square error of cross validation $)=3,15 ; \mathrm{x}_{1}=\mathrm{A} 290 ; \mathrm{x}_{2}=\mathrm{A} 295 ; \mathrm{x}_{3}=\mathrm{A} 300 ; \mathrm{x}_{4}=$ $\mathrm{A} 305 ; \mathrm{x}_{5}=\mathrm{A} 310 ; \mathrm{x}_{6}=\mathrm{A} 315 ; \mathrm{x}_{7}=\mathrm{A} 320$.

Tabel 3. Penentuan nilai FPM beberapa sampel tanaman

\begin{tabular}{|l|r|}
\hline Sampel & FPM* \\
\hline Ekstrak etanolik kulit batang faloak (prosedur A) & $4,54 \pm 3,15$ \\
\hline Fraksi etil asetat kulit batang faloak (prosedur A) & $9,49 \pm 3,16$ \\
\hline Ekstrak etanolik kulit batang faloak (prosedur B) & $6,81 \pm 3,15$ \\
\hline Ekstrak etanolik kangkung (prosedur A) & $8,00 \pm 3,16$ \\
\hline Ekstrak etanolik andong merah (prosedur A) & $14,86 \pm 3,15$ \\
\hline Krim ekstrak etanolik andong merah & $6,71 \pm 3,15$ \\
\hline
\end{tabular}

$* \mathrm{FPM}=$ rerata $\pm \Delta \mathrm{y}, \mathrm{FPM}$ dihitung dengan metode kuadrat terkecil sebagian, $\Delta \mathrm{y}$ merupakan perambatan kesalahan yang dihitung dari kesalahan prediksi (RMSECV) dan kesalahan acak (simpangan baku dari tiga kali pengukuran, $\sigma) ; \Delta y=\left(\mathrm{RMSECV}^{2}+\sigma^{2}\right)^{0,5}$

\section{DAFTAR PUSTAKA}

Bjørn-Helge Mevik, R.W. and K.H.L., 2015. pls: Partial Least Squares and Principal Component Regression. R package version 2.5-0. https://CRAN.R-

project.org/package $=$ pls.

Chauvet, C., Paparis, E., Coiffard, L., 2012. UV Filters , Ingredients with a Recognized Anti-Inflammatory Effect. PlosOne 7, 2-7.

Diffey, B.L., Robson, J., 1989. A New Substrate to Measure Sunscreen Protection Factors Throughout the Ultraviolet Spectrum. J. Soc. Cosmet. Chem. 40, 127-133.

Herzog, B., 2002. Prediction of Sun Protection Factors by Calculation of Transmissions with a Calibrated Step
Film Model. J. Cosmet. Sci. 53, 1126.

Ismartini, P., Sunaryo, S., 2010. The Jackknife Interval Estimation of Parametersin Partial Least Squares Regression Modelfor Poverty Data Analysis. IPTEK 21, 1-7.

ISO, 2010. Cosmetics - Sun Protection Test Methods - In Vivo Determination of The Sun Protection Factor (SPF) (ISO 24444:2010). UK.

Mansur, M.C.P.P.R., Leitão, S.G., Cerqueira-Coutinho, C., Vermelho, A.B., Silva, R.S., Presgrave, O.A.F., Leitão, Á.A.C., Leitão, G.G., RicciJúnior, E., Santos, E.P., 2016. In vitro and in vivo evaluation of Efficacy and Safety of Photoprotective Formulations Containing Antioxidant Extracts. Rev. Bras. Farmacogn. 26, 
$251-258$

Mishra, A., Mishra, A., Chattopadhyay, P., 2012. Assessment of In Vitro Sun Protection Factor of Calendula Officinalis L. (Asteraceae) Essential Oil Formulation. J. Young Pharm. 4, 17-21.

Sayre, R.M., Agin, P.P., LeVee, G.J., Marlowe, E., 1979. A Comparison of
In Vivo and In Vitro Testing of Sunscreening Formulas. Photochem. Photobiol. 29, 559-566.

Wold, S., Ruhe, A., Wold, H., Dunn III, W.J., 1984. The Collinearity Problem in Linear Regression. The Partial Least Squares (PLS) Approach to Generalized Inverses. SIAM J. Sci. Stat. Comput. 5, 735-743. 